\title{
Numeric modeling and estimating the performance characteristics of a pneumatic driven high pressure pump
}

\author{
Nikita Zhurkin ${ }^{1, *}$, Anatolij Donskoj ${ }^{1}$, and Aleksandr Zharkovskij $^{1}$ \\ ${ }^{1}$ Peter the Great St. Petersburg Polytechnic University, Institute of Energy and Transport Systems, \\ 195251, St. Petersburg, Russia
}

\begin{abstract}
Pneumatic driven high pressure pumps (PDHPPs), having a number of considerable advantages in comparison to other types of high pressure pumps, are widely used in different sectors of modern industry. However, estimating the performance characteristics of a PDHPP is complicated due to the specifics of physical processes taking place during its operation. A mathematical model was developed to solve this problem. Two main operating modes are considered: for constant load and for constant volume, which cover the most common uses of the PDHPPs. The solution of the model made it possible to estimate how various parameters affect the operation of the pump. Thus, with an increasing pressure of compressed air, the volume flow grows at the pump outlet; with a higher pressure of the pumped liquid due to compressibility and a higher load on the drive cylinder, the flow, on the contrary, reduces. In case the PDHPP operates for the constant volume, the time of pressure increase grows with an increase of the required pressure and the value of this volume. The mathematical model and computational data can be used in the development of new and modification of the existing pumps.
\end{abstract}

\section{Introduction}

Today high pressure pumps (HPPs) and pump systems based on them are widely used in various sectors of industry: machine-building, ship-building, aerospace, petrochemical and other industries. The overwhelming majority of HPPs are piston- or plunger-type positive displacement hydraulic machines of different configuration. The essential distinctions of HPPs are preconditioned by the type of drive, which can be mechanical, electromechanical, hydraulic or pneumatic. The type of drive determines the type of HPPs, their design, characteristics, operational specifics and application restrictions [1-5].

In the conditions of fire- and explosion-hazardous productions only pneumatic driven high pressure pumps (PDHPPs) can be used. A pneumatic driven high pressure pump is a positive displacement pneumohydraulic machine, which converts the energy of compressed air into the energy of pumped liquid with an increase of pressure. Apart from fire- and explosion-safety, PDHPPs have some other significant advantages in comparison to other

${ }^{*}$ Corresponding author: zhurkin47@ mail.ru 
types of HPPs, which ensures the application of PDHPPs in hydraulic systems of different applications. The main advantages of such pumps include high reliability, simple design, low weight, environmental safety, ease of installation, operation and repair, ability to pump aggressive and low-viscosity liquids. Such pumps are used in clamping mechanisms, water jet cutting machines, hand tools, lubricating systems, etc. PDHPPs are widely applied in testing equipment for checking the strength and tightness of vessels and pipelines.

The simplest design is an attribute of a single-acting PDHPP [6, 7], whose diagram is represented in Fig. 1.

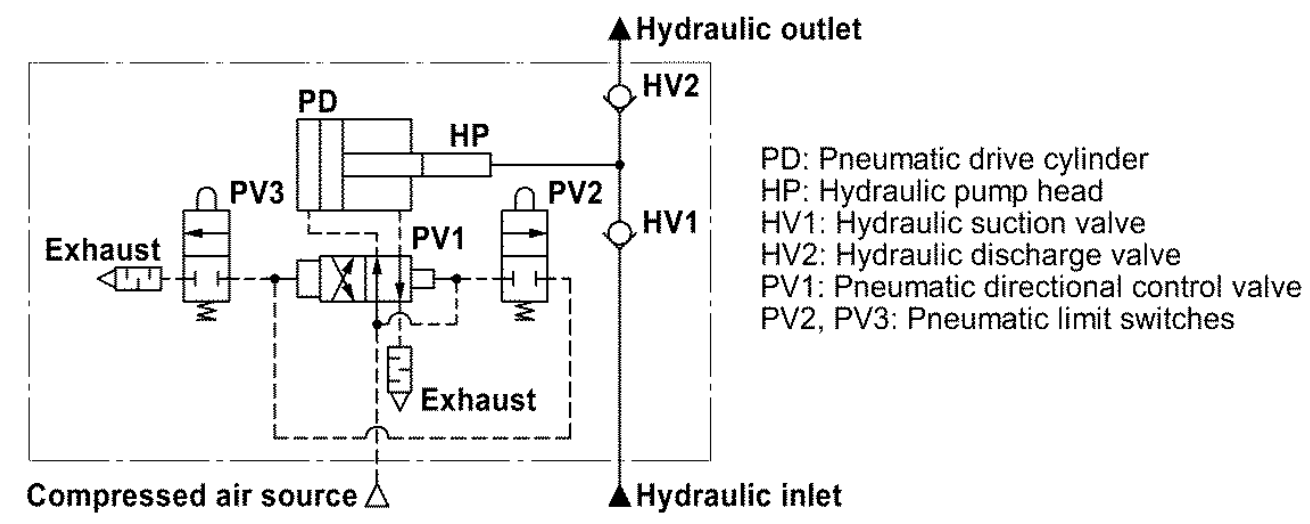

Fig. 1. Diagram of the PDHPP

Serially produced single-acting PDHPPs ensure the pressure at the outlet of the pump up to $400 \mathrm{MPa}$ and the volume flow up to $221 / \mathrm{min}[8,9]$.

An important parameter of single-acting PDHPPs is the coefficient of maximum pressure multiplication, determined by the design parameters of the PDHPP and expressed by the following ratio:

$$
i_{\text {max }}=\frac{A_{\mathrm{pd}}}{A_{\mathrm{hp}}},
$$

where $A_{\text {pd }}$ is the pneumatic drive piston surface area; $A_{\mathrm{hp}}$ is the pump plunger surface area.

Despite the simplicity of the design and operating principle of the single-acting PDHPP, determining its characteristics is complicated due to the specifics of physical processes that take place during operation of the pump. In literature the description of such pumps is presented in the paper [1], but it contains no methods for calculating the characteristics. The determination of the performance characteristics of a pneumohydraulic transformer - a device close in design to a PDHPP - is presented in the paper [10]. However, the author describes a double-acting pump, controlled by electro-pneumatic valves, with the pressure of the pumped liquid at the pump outlet not exceeding $2 \mathrm{MPa}$, which does not reflect the common operating modes of PDHPPs. Also, due to a low pressure built up by the device, the author does not consider the operation of the pump for a closed volume, corresponding to the schemes of the majority of testing facilities. Similar devices are considered in the papers $[11,12]$. However, the same as in the previous work, these devices work at low pressures. Moreover, they serve to pump gas, which does not make it possible to apply the provided results to estimate the characteristics of PDHPPs.

Thus, the problem of developing a method for calculating the characteristics of a PDHPP in various operating modes is important.

\section{Methods}


A mathematical model of the PDHPP is provided to solve this problem. The model is developed in accordance with the design diagram, presented in Fig. 2.

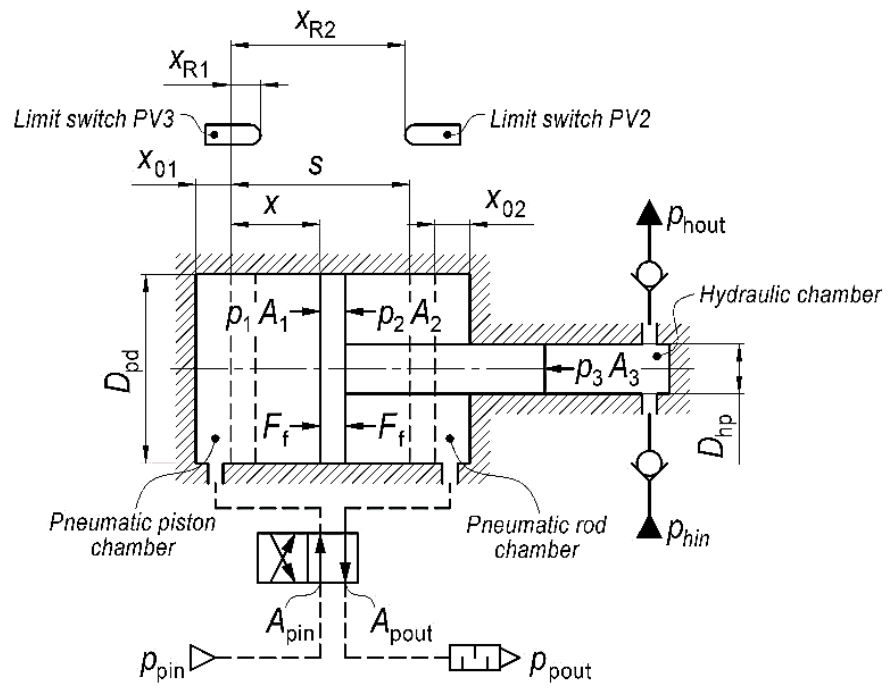

Fig. 2. Design diagram of the PDHPP

When the mathematical model was developed the following assumptions were made: gas-dynamic processes are adiabatic in the chambers of the pneumatic drive cylinder and isothermal in the pneumatic lines, the switching of the valves is instantaneous, the suction and discharge hydraulic valves do not develop resistance of liquid flow, there is no deformation of the structural elements of the pump, the bulk modulus of liquid remains constant, at the suction stroke the hydraulic chamber fully fills with liquid [4, 13-20]. In order to describe the operation of the PDHPP, an equation of piston motion and an equation of pressure change in the chambers of the pneumatic drive and hydraulic pump are set up. form:

The equation of the pump piston motion in accordance with Fig. 2 has the following

$$
m \ddot{x}=p_{1} A_{1}-p_{2} A_{2}-p_{3} A_{3}-F_{\mathrm{f}},
$$

where $m$ - the weight of the pump piston; $x$ is the coordinate of the piston position; $p_{1}-$ the pressure in the piston chamber; $p_{2}$ is the pressure in the rod chamber; $p_{3}$ is the pressure in the hydraulic chamber; $A_{1}$ is the surface area of the piston chamber; $A_{2}$ is the surface area of the rod chamber; $A_{3}$ is the surface area of the hydraulic chamber; $F_{\mathrm{f}}$ is the friction force.

The laws of pressure change in the piston and rod ends of the drive cylinder at the pumping stroke have the following form:

$$
\left\{\begin{array}{l}
\dot{p}_{1}=\frac{k A_{\text {pin }} \sqrt{R T}}{A_{1}\left(x+x_{01}\right) \sqrt{\zeta_{\text {pin }}}} \sqrt{p_{\text {pin }}^{2}-p_{1}^{2}}-\frac{k p_{1}}{x+x_{01}} \dot{x}, \\
\dot{p}_{2}=-\frac{k A_{\text {pout }} \sqrt{R T}}{A_{2}\left(s-x+x_{02}\right) \sqrt{\zeta_{\text {pout }}}}\left(\frac{p_{2}}{p_{\text {pin }}}\right)^{\frac{k-1}{2 k}} \sqrt{p_{2}^{2}-p_{\text {pout }}^{2}}+\frac{k p_{2}}{s-x+x_{02}} \dot{x},
\end{array}\right.
$$

where $k$ is the adiabatic index; $A_{\text {pin }}, A_{\text {pout }}$ are surface areas of the inlet and outlet ports; $T$ is the temperature of the compressed air in the pneumatic supply line; $R$ is the absolute gas constant; $x_{01}, x_{02}$ are the reduced coordinates of the dead volume of the piston and rod 
chambers; $\zeta_{\text {pin }}, \zeta_{\text {pout }}$ are the resistance coefficients of the inlet and outlet ports; $p_{\text {pin }}$ is the pressure of the compressed air in the pneumatic supply line; $p_{\text {pout }}$ is the pressure of the air in the pneumatic exhaust line.

Similarly, for the suction stroke:

$$
\left\{\begin{array}{l}
\dot{p}_{1}=-\frac{k A_{\text {pout }} \sqrt{R T}}{A_{1}\left(x+x_{01}\right) \sqrt{\zeta_{\text {pout }}}}\left(\frac{p_{1}}{p_{\text {pin }}}\right)^{\frac{k-1}{2 k}} \sqrt{p_{1}^{2}-p_{\text {pout }}^{2}}-\frac{k p_{1}}{x+x_{01}} \dot{x}, \\
\dot{p}_{2}=\frac{k A_{\text {pin }} \sqrt{R T}}{A_{2}\left(s-x+x_{02}\right) \sqrt{\zeta_{\text {pin }}}} \sqrt{p_{\text {pin }}^{2}-p_{2}^{2}}+\frac{k p_{2}}{s-x+x_{02}} \dot{x} .
\end{array}\right.
$$

The change of pressure in the hydraulic pump body is related to the compression of the pumped liquid and is determined by the following equation:

$$
\dot{p}_{3}=\frac{E}{V_{3}} A_{3} \dot{x},
$$

where $E$ is the bulk modulus of the pumped liquid; $V_{3}$ is the volume of the pump hydraulic chamber. The volume of the hydraulic chamber $V_{3}$ consists of the effective volume and the dead volume, not participating in liquid pumping:

$$
V_{3}=V_{\mathrm{e}}+V_{\mathrm{d}}
$$

where $V_{\mathrm{e}}$ is the effective volume of the hydraulic chamber; $V_{\mathrm{d}}$ is the dead volume.

The friction force, acting on the piston of the PDHPP, consists of sliding friction force and viscous friction force:

$$
F_{\mathrm{f}}=\mu_{\mathrm{s}} F_{\mathrm{n}}+\mu_{\mathrm{v}} \dot{x}
$$

where $\mu_{\mathrm{s}}$ is the sliding friction coefficient; $F_{\mathrm{n}}$ is the force normal to internal surfaces of the pump and acting in the sealing nodes; $\mu_{\mathrm{v}}$ is the viscous friction coefficient.

Equations (2) - (7) describe the operation of the PDHPP at constant pressure of the pumped liquid at the pump outlet.

Practical problems are often about the operation of the PDHPP for constant volume, in particular, in various testing facilities and clamping mechanisms. The basic diagram of such a hydraulic system is presented in Fig. 3 .

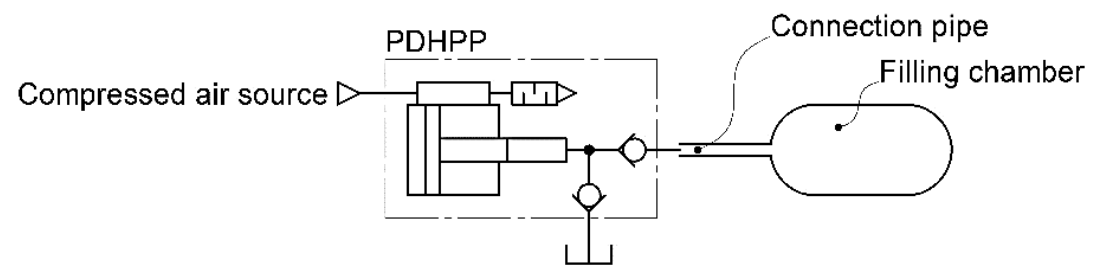

Fig. 3. Diagram of the PDHPP operating for constant volume

To describe the operating process of the PDHPP for constant volume and the process of pressure build-up in it, the equations (2) - (7) must be supplemented with the equation of pressure change in the attached volume:

$$
\dot{p}_{\mathrm{AV}}=\frac{E}{V_{\mathrm{AV}}} A_{3} \dot{x},
$$


where $V_{\mathrm{AV}}$ is the reduced volume of the attached chamber. The reduced volume $V_{\mathrm{AV}}$ is composed of the volume of the filling chamber and the volume of the pipeline connecting it to the pump:

$$
V_{\mathrm{AV}}=V_{\mathrm{FC}}+V_{\text {pipe }}
$$

where $V_{\mathrm{FC}}$ is the volume of the filling chamber; $V_{\text {pipe }}$ is the volume of the connection pipeline.

\section{Results and Discussion}

The main parameters of the PDHPP accepted for mathematical modeling are presented in Table 1.

Table 1. Main parameters of PDHPP

\begin{tabular}{|l|c|}
\hline \multicolumn{1}{|c|}{ Parameter } & Value \\
\hline Pneumatic drive piston diameter $D_{\mathrm{pd}}$ & $0.150 \mathrm{~m}$ \\
Pneumatic drive rod area $D_{\mathrm{hp}}$ & $0.012 \mathrm{~m}$ \\
Piston total travel $s$ & $0.060 \mathrm{~m}$ \\
Switch valve position $x_{\mathrm{R} 1}$ & $0.003 \mathrm{~m}$ \\
Switch valve position $x_{\mathrm{R} 2}$ & $0.057 \mathrm{~m}$ \\
Inlet pneumatic channel diameter $D_{\text {pin }}$ & $0.006 \mathrm{~m}$ \\
Outlet pneumatic channel diameter $D_{\text {pout }}$ & $0.012 \mathrm{~m}$ \\
\hline
\end{tabular}

The results of modeling the PDHPP operation in case of constant load operation are presented in Figures 4-6. Figures 4 and 5 respectively present the time variance graphs of instantaneous flow rate of the PDHPP at different pressure values of the pumped liquid at the pump outlet and at different pressure values of the compressed gas in the pump inlet.

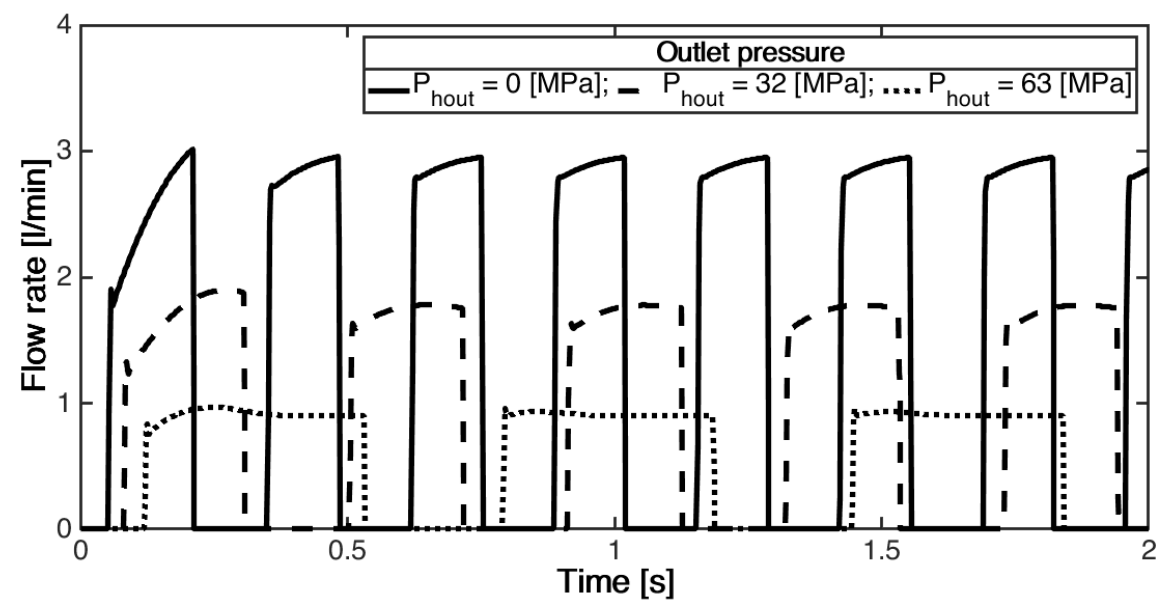

Fig. 4. Graphs of flow rate of the PDHPP $\left(p_{\text {pin }}=0.63 \mathrm{MPa}\right)$ 


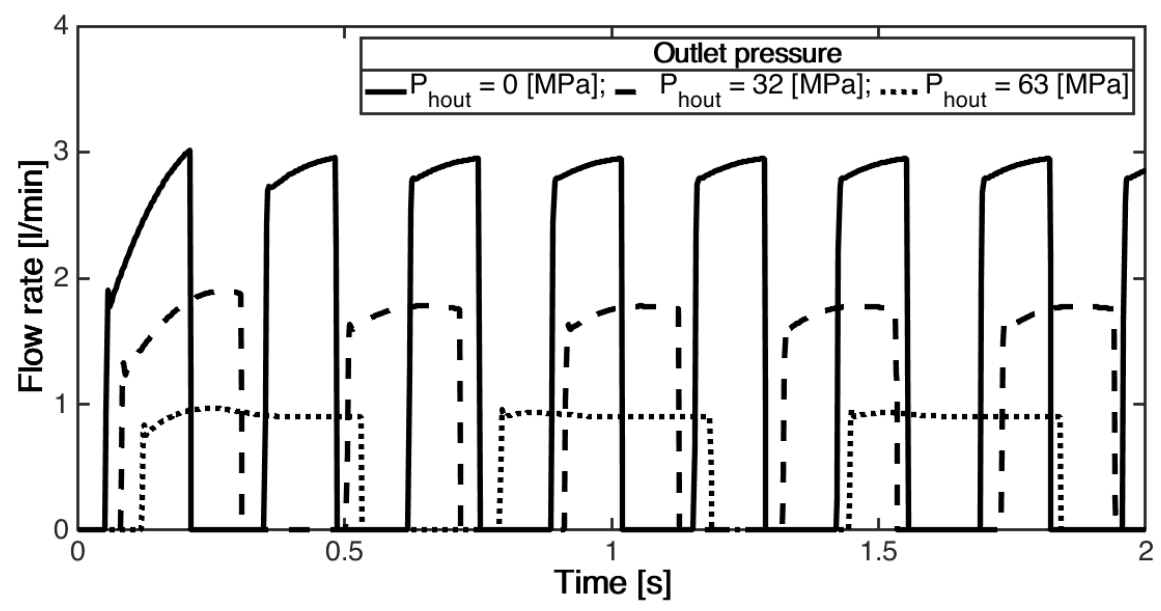

Fig. 5. Graphs of flow rate of the PDHPP ( $\left.p_{\text {hout }}=32 \mathrm{MPa}\right)$

It is seen in Figures 4 and 5 that with a growing pressure of the pumped liquid at the outlet of the PDHPP, its volume rate decreases. There are two causes of that: firstly, with a growing pressure of the pumped liquid, the load on the drive pump increases and, consequently, the rpm of the PDHPP reduces; secondly, with a growing pressure of the pumped liquid, the losses due to its compression in the hydraulic chamber go up. If the pressure of the pumped liquid at the pump outlet is close to maximum possible, defined by the expression (1), the flow rate reduces more intensively. With an increasing pressure of compressed air the volume flow, on the contrary. grows. When the maximum possible pressure is achieved, the flow rate falls to zero. This dependence of the volume flow rate on the pressure of the pumped liquid at the pump outlet is presented in Fig. 6. This dependence is not common for most HPPs, where the flow rate does not depend a lot on the liquid pressure and is preconditioned by the operating principle of pneumatic drive pumps. The operating mode with zero flow rate is normal for PDHPPs.

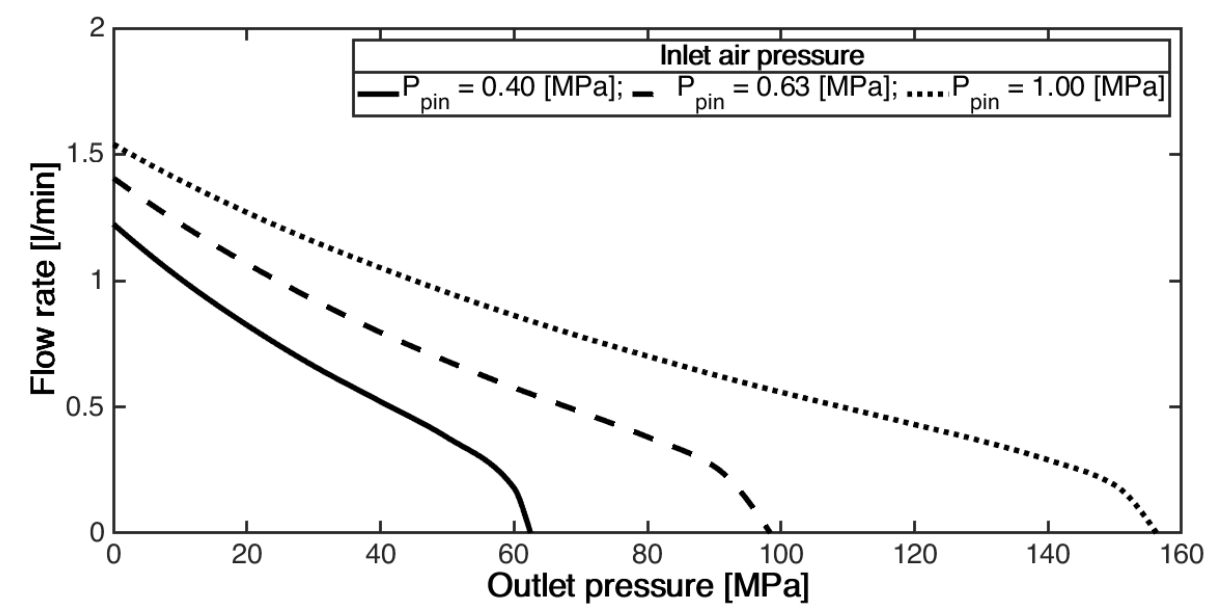

Fig. 6. Graph of pump flow rate dependence on pressure

When PDHPPs operate for constant volume, the practical value is presented by the time of pressure growth in this volume. Figure 7 illustrates the dependence graph of pressure growth time at various values of the attached volume. 


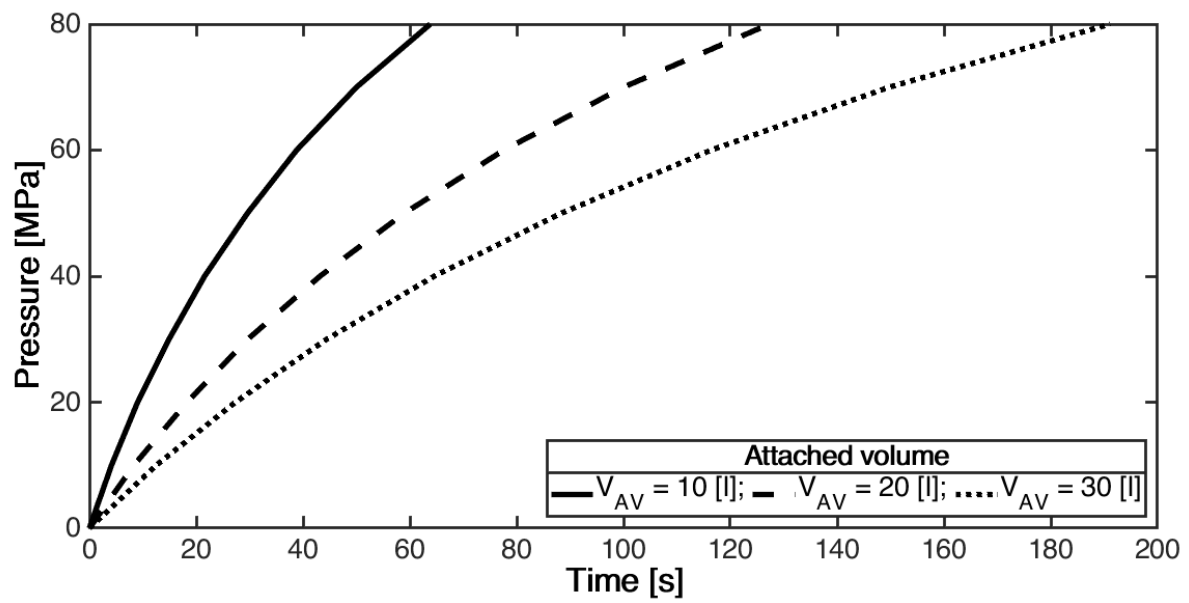

Fig. 7. Graph of pressure growth in attached volume $\left(p_{\text {pin }}=0.63 \mathrm{MPa}\right)$

Fig. 7 shows that with growth of the desired pressure or increase of the attached volume, the time of pressure build-up increases considerably. It is related to the causes similar to those in case of the constant load operating mode: with the pressure growing in the attached volume, the load on the drive pneumatic cylinder grows too, which reduces the operating frequency of the pump. At the same time, the liquid in the attached volume is compressed and the bigger the volume is, the more liquid is required to make the pressure grow in it. The following conclusion can be made from the above: in case the PDHPP operates for the constant volume, the length of coupling hydraulic lines must be as short as possible to exclude excessive losses of the pump flow rate on the compression of the pumped liquid.

\section{Conclusions}

The developed mathematical model allows to estimate the performance characteristics and to research the operation of the PDHPP at various design and operating parameters, such as pressure of the compressed air, pressure of the pumped liquid, value of the attached volume. The numerical simulation made it possible to estimate how these parameters affect the operation of the pump.

1. With an increasing pressure of the compressed air, the volume flow grows, with an increasing pressure of the pumped liquid the volume flow, on the contrary, reduces. In addition, the pump flow decreases with the growth of dead volumes of pneumatic and hydraulic chambers.

2. In case the PDHPP operates for the constant volume, the time of pressure increase grows with an increase of the required pressure and the value of this volume. It is important to reduce the length of hydraulic coupling lines to minimize losses on compression of the pumped liquid.

3. The performance characteristics of the pump obtained from the results of numerical simulation qualitatively coincide with the characteristics of serially produced single-acting PDHPPs.

The developed mathematical model can be used to design new pumps and modify the existing ones, as well as to investigate their operation as part of various hydraulic systems.

Further research will be dedicated to the improvement of the mathematical model of PDHPPs, mathematical modeling of the pneumatic control valves, deformation of structural elements of the pump, and heat exchange. 


\section{References}

1. E Gerc, A. Kudryavcev, O. Lozhkin, Pnevmaticheskie ustroystva $i$ sistemy $v$ mashinostroenii (1981)

2. M. T. Gracey High-pressure pumps (2006)

3. Y. Laptev, V. Gluhov, Y. Yakimenlo, G. Teterin, Gidrosistemy vysokih davlenij (1973)

4. T. Bashta, Ob'emnye nasosy i gidravlicheskie dvigateli gidrosistem (1974)

5. I. Chinyaev, Porshnevye nasosy (1966)

6. Jr. Bixby, W. Willard, Pneumatically controlled rate pump: US patent US4405292A (1983-09-20)

7. K. Roediger, Hydraulic pressure producer - has pneumatically-driven hydraulic piston pump with valves and fluid container integrated in square block: German patent 4120845A1 (1993-06-25)

8. Haskel Pneumatic driven liquid pumps [online] Available at: https://www.haskel.com/wp-content/uploads/Haskel_Liquid_Pumps_Booklet_Web.pdf

9. Parker ASL Pumps Standard 6" Air Liquid Product Catalogs [online] Available at: http://www.parker.com/Literature/Instrumentation\%20Products\%20Division\%20Europe/Te chnical\%20Catalogues/ASL\%20Series.pdf

10. Y. Shi, T. Wu, M. Cai, C. Liu J. Mech. Sci. \& Tec. 30 (3) 1163-1170 (2016)

11. Y. Shi, M. Cai, W. Xu, J. Lu, Chin. J. Mech. Eng. 25 (5) 889-896 (2012)

12. Y. Shi, M. Cai, J. Zhejiang Univ.-Sci. A. (Appl. Phys.\& Eng.) 13 (6) 481-490 (2012)

13. A. Donskoj, Modelirovanie perehodnyh processov v pnevmaticheskih sistemah (1998)

14. A. Donskoj, Matematicheskoe modelirovanie processov v pnevmaticheskih privodah (2009)

15. E. Gerc, G. Krejnin, Dinamika pnevmaticheskih privodov mashin-avtomatov (1964)

16. E. Gerc, V. Zenchenko, G. Krejnin, Sintez pnevmaticheskih privodov (1966)

17. T. Bashta, Mashinostroitel'naya gidravlika (1971)

18. P. Beater, Pneumatic drives (2007)

19. V. Pogorelov, Gazodinamicheskie raschety pnevmaticheskih privodov (1971)

20. D. Popov, Mehanica gidro- i pnevmoprivodov (2001) 